\title{
MODOS INDÍGENAS DE PRODUÇÃO E TRANSMISSÃO DE CONHECIMENTO: reflexões introdutórias a partir do povo indígena Kiriri/BA
}

\author{
José Valdir Jesus de Santana* \\ Camila Silva de Oliveira**
}

\begin{abstract}
Resumo: Essa pesquisa tem por objetivos analisar os modos de produção e transmissão de conhecimento e, portanto, das "experiências de aprendizagem" que indígenas Kiriri acionam para se produzirem enquanto coletivo; compreender os sentidos de aprendizagem e do que é importante aprender, seja no que diz respeito aos "conhecimentos indígenas", quanto aos "conhecimentos escolares" tanto por parte dos adultos quanto das crianças. Trata-se, portanto, de um estudo etnográfico desenvolvido junto a famílias Kiriri que habitam a cidade de Jacobina, Bahia. Nesse texto, especificamente, situamos o debate, a partir de etnografias elaboradas em contexto indígena, que buscam pensar a relação entre produção e circulação de conhecimentos indígenas, em muitos casos mediados pelas próprias crianças desses coletivos.
\end{abstract}

Palavras-chave: aprendizagem, conhecimento, povos indígenas

\section{INDIGENOUS WAYS OF PRODUCTION AND TRANSMISSION OF KNOWLEDGE: introductory} reflections from the Kiriri people, Bahia, Brazil

\begin{abstract}
This research aims to analyze the ways of production and transmission of knowledge and, therefore, the "learning experiences" that indigenous Kiriri activate to produce themselves as a collective; understand the senses of learning and of what is important to learn, either with regard to "Indigenous knowledge" and "school knowledge" both in adults and children. It is, therefore, an ethnographic study developed along with Kiriri families that inhabit Jacobina, Bahia, Brazil. In this text, specifically, we situate the debate, based on elaborated ethnographies in the context of indigenous people, who attempt to reflect on the relation between production and circulation of indigenous knowledge, in many cases mediated by the children of these collectives.
\end{abstract}

Keywords: learning, knowledge, indigenous people

\footnotetext{
* Doutor em Antropologia Social pela Universidade Federal de São Carlos. Professor adjunto da Universidade Estadual do Sudoeste da Bahia. É professor no Programa de Pós-Graduação em Relações Étnicas e Contemporaneidade e no Programa de Pós-Graduação em Ensino. E-mail: santanavaldao@yahoo.com.br

** Graduada em Pedagogia pela Universidade Federal do Recôncavo da Bahia; mestranda no Programa de Pós-Graduação em Relações Étnicas e Contemporaneidade da Universidade Estadual do Sudoeste da Bahia; professora da rede municipal de Feira de Santana, BA. E-mail: camila mirandaso@,hotmail.com
} 


\section{Introdução}

Segundo Macedo de Sá (2013), em pesquisa realizada junto aos Kiriri, é no Toré, nas “obrigações” nas matas, assim como nas atividades diárias realizadas, na farinhada, no batalhão para limpar as roças, para despalha do milho, para fabricar artesanatos, para construir casas, nas mobilizações étnicas, que os pequenos Kiriri, assim como os jovens, homens e mulheres, estão sempre presentes, aprendendo a ser membro do seu povo (p. 134). Nesse sentido, os Kiriri compreendem a aprendizagem como um processo social e o conhecimento como algo que se constitui na rica experiência da vida cotidiana.

Essa pesquisa tem por objetivos analisar os modos de produção e transmissão de conhecimento e, portanto, das "experiências de aprendizagem" que indígenas Kiriri acionam para se produzirem enquanto coletivo; compreender os sentidos de aprendizagem e do que é importante aprender, seja no que diz respeito aos "conhecimentos indígenas", quanto aos "conhecimentos escolares" tanto por parte dos adultos quanto das crianças. Trata-se, portanto, de um estudo etnográfico desenvolvido junto a famílias Kiriri que habitam a cidade de Jacobina/BA. No caso das famílias Kiriri de Jacobina, a prática do artesanato e seu aprendizado tem se colocado como central, tanto no sentido de uma "experiência cultural", que requer certas babilidades, educação da atenção (INGOLD, 2010) como também enquanto marcador de "indianidade" que se coloca "para fora", sobretudo a partir da venda do artesanato. Concordamos com Coelho e Debortoli (2012, p. 132) quando afirmam que "aprendemos porque participamos e compartilhamos a vida, relacionando-nos como seres, humanos e não humanos, com os artefatos, com as coisas, compartilhando centralidade, relações e formas de participação". O que buscamos, inspirados também por Gomes (2014), Cohn (2000a, 2000b, 2000c, 2002), Tassinari (et al., 2017) é trazer à cena uma concepção de aprendizagem, de produção e circulação de conhecimento [e também de educação] mais próxima da experiência cotidiana.

Cabe ressaltar que as reflexões apresentadas nesse texto, mesmo que introdutórias, fazem parte de uma pesquisa de mestrado que se encontra em andamento junto ao Programa de Pós-Graduação em Relações Étnicas e Contemporaneidade, da Universidade Estadual do Sudoeste da Bahia.

\section{Conhecimentos indígenas e modos de produção: algumas proposições}

A etnologia tem demonstrado que produzir conhecimento, em diferentes contextos indígenas, implica na produção de corpos e pessoas, na ativação de determinados órgãos e sentidos, de modo que tais processos não podem ser pensados em separado. "O conhecimento reside no corpo" (CARNEIRO DA CUNHA, 2014, p. 14), como já demonstraram Oliveira (2012), Cohn (2000a, 2000b, 2000c, 2001,

\footnotetext{
1 "É através de um processo de habilitação (enskilment), não de enculturação, que cada geração alcança e ultrapassa a sabedoria de suas predecessoras. Isto me leva a concluir que, no crescimento do conhecimento humano, a contribuição que cada geração dá à seguinte não é um suprimento acumulado de representações, mas uma educação da atenção” (INGOLD, 2010, p. 7).
} 
2002a, 2002b, 2005a, 2005b, 2013), Alvares (2004), McCallum (1998, 2011), Lima (2014), Góes (2012), Borges e Niemeyer (2012), Saez, Naveira e Gil (2003), Tassinari (2014a, 2014b), Melo (2014), dentre outros.

$\mathrm{Na}$ construção de uma paisagem sobre/por/entre o conjunto de processos educativos que envolve a socialização dos sujeitos constituídos pelo sistema cultural de um povo, a educação de que trataremos aqui rompe com a limitação do conceito às práticas pedagógicas escolares para pensarmos como a cultura produz modos de educar. Sob esta ótica, o conhecimento, assim como o modo de conhecer/educar é cultural, ao passo que as instâncias culturais e os processos culturais têm suas próprias pedagogias. De acordo com Gersem José dos Santos Luciano (2006) são os processos educativos e os saberes por eles transmitidos que garantem a produção de uma cultura e identidade que se faz na diferenciação com os demais povos. Sendo assim,

Ao articular instituições, valores e práticas, em integração dinâmica com outros sistemas sociais, como a economia, a política, a religião, a moral, os sistemas educacionais têm como referência básica os projetos sociais (ideias, valores, sentimentos, hábitos etc.) que lhes cabem realizar em espaços e tempos sociais específicos (LUCIANO, 2006, p.129).

A noção indígena de educação, conforme Tassinari (2011, p. 12), “[...] não se dirige apenas à transmissão de ideais, conhecimentos, técnicas e valores, mas reconhece que aquilo que se sabe é 'incorporado', toma assento no corpo, e este deve ser adequadamente produzido para receber conhecimento".

As pesquisas etnográficas no campo da antropologia da educação e da antropologia da criança composta pelos trabalhos de Lopes da Silva (2002), Cohn (2005b), Codonho (2007), Tassinari (2012), Alvares (2012), Tassinari e Cohn (2012), Melo (2012), Melo e Giraldin (2012), dentre outros, referentes aos diferentes povos indígenas e suas múltiplas concepções de infância, formas de aprender e ensinar, têm produzindo rastros de uma antropologia de reconhecimento da criança como produtora de sociabilidade, de relações sociais e de protagonistas das experiências dando-lhes sentidos e significação, e, portanto, enquanto interlocutoras das pesquisas.

Tais pesquisas têm mostrado que a centralidade da infância para as cosmologias indígenas se apresenta contrária à visão adultocêntrica do pensamento ocidental, visto que os processos nativos de aprendizagem têm revelado noções de "criança" diferenciadas entre os povos, como também a importância das mesmas em processos decisórios para a cultura e socialização de seus povos. Destarte, Clarice Cohn (2005) nos adverte que a concepção de infância a partir de uma visão dual de inocência e incompletude pela qual eram tratadas as crianças na história ocidental se constitui como um modo particular de pensar a infância, e não universal. Alertando-nos para a necessidade de compreendermos que são as vivências das crianças que constituem o mundo particular infantil, sendo atuantes na consolidação das relações e dos papéis que assumem. De forma que as conclusões destas pesquisas têm constituído algumas bases para a investigação com crianças indígenas e educação indígena, como sintetiza Antonella Maria Imperatriz Tassinari (2007): 
Verificamos que, ao contrário da visão adultocêntrica do pensamento ocidental, o pensamento indígena coloca as crianças como mediadoras entre categorias cosmológicas de grande rendimento: mortos/vivos, homens/mulheres, afins/consanguíneos, nós/outros, predação/produção. Igualmente, ao contrário de nossa prática social que exclui as crianças das esferas decisórias, as crianças indígenas são elementos-chave na socialização e na interação de grupos sociais e os adultos reconhecem nelas potencialidades que as permitem ocupar espaços de sujeitos plenos e produtores de sociabilidade (TASSINARI, 2007, p. 22-23).

Sheila Alves de Araújo (2014) analisou as produções científicas referentes às crianças indígenas, entre 2001 e 2012, disponíveis no banco de dados de dissertações e teses da CAPES, identificando 63 trabalhos, em diferentes áreas do conhecimento (Educação, Antropologia, Letras, Pediatria, Odontologia, Linguística, Saneamento e Meio Ambiente, Saúde Coletiva, Psicologia, Farmácia, Saúde Pública, Direito, Nutrição, Ciências da Saúde, Música, Educação Física/Lazer, Ciências Sociais, História e Ciências Biológicas), o que demonstra a diversidade de abordagem e de perspectivas teórico/analíticas em que se têm discutido as questões em torno das crianças e infâncias indígenas. Segundo a autora, há uma predominância de trabalhos realizados no campo da Educação que, no caso de sua pesquisa, representou um total de 20 trabalhos (treze dissertações e 7 teses).

Conforme Araújo (2014), há certa predominância, nos trabalhos analisados, da ideia de que os processos de transmissão de conhecimento e da aprendizagem, em contexto indígena, ocorrem a partir das interações que as crianças estabelecem entre seus pares na vivência cotidiana, em que a criança aprende experimentando, imitando, criando, inventando e vivenciando o dia a dia na aldeia, observando e acompanhando a vida dos mais velhos, uma vez que o ambiente familiar proporciona às crianças liberdade e autonomia necessárias para experimentar e criar sem as interferências constantes dos adultos. Diferentemente da visão ocidental de educação fragmentada e por etapas, o entendimento dos povos indígenas é de que,

[...] a educação indígena se refere a um conjunto de atividades ou rotinas, valores, crenças, hábitos, herança cultural e práticas próprias da infância (jogos, brinquedos e brincadeiras) estabelecidos nas interações entre os pares, expressando uma forma de ver e sentir o mundo ao seu redor, ou seja, a criança como agente ativo de transformação, elaboração e recriação da cultura (ARAÚJO, 2014, p. 126).

Ademais, na perspectiva de Araújo,

A educação indígena é trabalhada de duas formas: A primeira é a educação tradicional que possibilita a vida cotidiana, afazeres domésticos, rituais, práticas de embelezamento e pintura corporal, brincadeiras, músicas, histórias, reuniões que precedem aos rituais e às relações familiares. Já a segunda é a educação escolar que permite às populações indígenas se apropriarem dos conhecimentos da sociedade branca a fim de lutarem por seus direitos (2014, p. 143).

$\mathrm{Na}$ contemporaneidade, as reformulações de conceitos como agência, cultura, ação social, educação e sociedade produzidos pelo novo campo da antropologia da criança e antropologia da educação contribuíram para a produção de novas perspectivas epistemológicas e de conhecimentos sobre como outras culturas e sociedades podem ter múltiplas formulações em relação ao que é ser criança e aos 
modos de aprender. Cohn (2005) pontua que, “[...] não podemos falar de crianças de um povo indígena, sem entender como esse povo pensa, o que é ser criança e sem entender o lugar que elas ocupam naquela sociedade" (2005, p. 9).

Estes repertórios discursivos também apontam que a educação indígena não é um projeto finito e definido, ao contrário, as pesquisas têm mostrado a diversidade de noções e de experiências culturais de conhecimentos e aprendizagem na vida social dos grupos indígenas, através das quais produzem mecanismos de processos cognitivos particulares (TASSINARI, 2012).

Os saberes ancestrais são transmitidos oralmente de geração em geração, permitindo a formação de músicos, pintores, artesões, ceramistas ou cesteiros, além de todos saberem cultivar a terra e a arte de caçar e pescar. Os pais e os avós são os responsáveis por transmitir aos seus filhos ou netos, desde a mais tenra idade, a sabedoria aprendida de seus ancestrais. Assim, as crianças desde cedo vão aprendendo a assumir desafios e responsabilidades que thes permitam inserir-se na vida social e o fazem, principalmente, por meio da observação, da experiência empírica e da autorreflexão proporcionadas por mitos, histórias, festas, cerimônias e rituais realizados para tal fim (LUCIANO, 2006, p.130).

Logo, a educação indígena se refere aos processos próprios de educação tradicional dos povos indígenas, cujas aprendizagens dos costumes e saberes se constituem enquanto uma das estratégias próprias de vivência sociocultural mantedora de suas alteridades. De acordo com Carneiro da Cunha $(2009,2012)$ a marca principal dos saberes ou conhecimentos tradicionais indígenas é a forma como estes são produzidos e atualizados/reproduzidos, operando por um processo coletivo e acumulativo e, não o seu conteúdo ou sua antiguidade. Tais práticas estabelecidas nas relações possibilitam a reprodução pelas novas gerações do modo de ser e da cultura de cada povo indígena. Nesse sentido, “[...] o que importa não é apenas preservar os conhecimentos tradicionais, e sim se engajar em conservar vivos e dinâmicos esses sistemas ‘outros' de conhecimento”' (CARNEIRO DA CUNHA, 2014, p. 16).

Aracy Lopes da Silva (2002) identificou em pesquisas realizadas entre o período de 1971 a 1995 os processos de ensino e aprendizagem dos Akwe, apontando para uma concepção de que o aprendiz precisa aprender a aprender, na qual audição prevalece sobre a fala, sendo que os falantes são os que detêm o conhecimento. A experimentação da vida cotidiana conduz a aprendizagem pela observação e pela corporalidade, cujos rituais corporais e a relação com outros domínios cósmicos constituem processos cognitivos de produção de uma memória corporal. Percebe-se, também, que cabe ao aprendiz da educação indígena Xerente a disposição em percorrer o caminho para o conhecimento, em que o atributo primordial de sua educação é a autonomia e a liberdade dos indígenas no processo de ensinoaprendizagem. Para adquirir o aprendizado e se tornar bom aprendiz Xerente é necessário persistência, atenção e tempo (MELO e GIRALDIN, 2012).

Bergamaschi (2005), em sua etnografia sobre as crianças Guarani Mbyá localizadas no Rio Grande do Sul, apresenta um modo específico de aprender guarani em consenso com um ser-estar no mundo. A cosmologia guarani compreende que as pessoas vêm ao mundo com características singulares, de modo que o respeito e o cuidado são os princípios norteadores de sua educação, voltada mais para a orientação 
do que para o julgamento e/ou punição. Destacando a curiosidade como uma característica primordial para o movimento de quem deseja aprender com o coração, as práticas educativas se fundamentam na oralidade, na paciência e na necessidade da repetição para memorizar.

A pesquisa de mestrado de Camila Guedes Codonho (2007), realizada entre os Galibi-Marworno, trata das noções de práticas de ensino e aprendizagem e de infância deste povo localizado no norte do estado do Amapá. A autora acompanha as significações e o papel social que as crianças ocupam nesta sociedade, demonstrando a importância das ações infantis na produção de conhecimento e manutenção das tradições culturais, verificando a existência de redes de trocas de conhecimentos estabelecidas entre pares; as crianças são constituídas de saberes e aprendem entre si a partir de uma transmissão horizontal, ampliando a percepção de que os saberes só seriam transmitidos verticalmente das gerações mais velhas para as mais novas. Cada ciclo com seus modos de significações e de produção de saberes, que se diferenciam, mas não se anulam. Segundo autora,

É no contexto dos hãs que o aprendizado horizontal se dá intensamente, já que é nesse núcleo que as crianças podem conviver umas com as outras sem restrições. Os saberes transmitidos nesse contexto dizem respeito tanto às brincadeiras, obrigações diárias, cosmologias, mitologia, etnoconhecimentos, até a percepção das regras matrimoniais, como a constatação, desde bem cedo, de que só pode casar com quem não se brinca na infância e, em alguns casos, com quem se briga (CODONHO, 2012, p. 68).

Os estudos de Adir Casaro Nascimento (2011) também evidenciaram modos próprios de ser das crianças indígenas Kaiowá, que dizem respeito à perspectiva da pedagogia indígena. Suas sabedorias infantis são construídas na experimentação cotidiana, com a observação, a imitação, e a invenção do que acompanham na vida dos mais velhos. Deste modo, as brincadeiras das crianças são consideradas importantes para a transmissão cultural, cujas significações e identidades são construídas de forma autônomas e livre.

Ângela Nunes (2002), ao apresentar as experiências de infância A'uwê-Xavante, assinala a autonomia de movimento e de circulação espaço/temporal das crianças, permitindo sua rica participação no universo sociocultural desse povo.

[...] Ir a todos os lugares, andar atrás desta ou daquela pessoa, ouvir as conversas dos outros, experimentar fazer de tudo um pouco, distrair-se com isto ou aquilo são privilégios das crianças e elas os usam com toda a propriedade, colocando-se a par do que se passa com todos os da aldeia, bem como das notícias que chegam de fora. Essa prática é legítima e gera entre as crianças e os adultos um tipo de relacionamento diferente do que os segundos estabelecem entre si, sobrepondo-se a uma série de exigências societárias que, explicitamente, verificam-se em classes de idades posteriores (NUNES, 2002, p. 72).

A participação das crianças nas tarefas do grupo revela aspectos do processo educativo entre os A'uwê-Xavante. A atitude tolerante da parte do adulto para as iniciativas e produções das crianças pode ser identificada durante a participação das mesmas nas tarefas do grupo. As iniciativas de participação das crianças são aceitas e elas são livres para fazerem e ajudarem como podem, sem que haja crítica por parte dos adultos. 
Cohn (2000a, 2000b, 2005) também enfatiza a centralidade das crianças Xikrin na produção da vida cotidiana, demonstrando que elas “[...] não simplesmente aprendem as relações sociais em que têm e terão que se engajar ao longo da vida, mas atuam em sua configuração" (2005, p. 28). A autonomia, a participação e a circulação das crianças também foram observadas pela antropóloga. Segundo a autora, “[...] elas atuam como mensageiras, posto que os Xikrin as consideram como não possuidoras de pia'am (vergonha), que caracteriza a relação dos adultos entre si” (COHN, 2000a, p. 71).

As crianças xikrin, portanto, realizam, assim como os adultos, essa intersecção entre as relações sociais que recebem das gerações anteriores e aquelas que põem em prática e atualizam (ou, nos termos de Strathern, "ativam"). Vale dizer que essa construção pessoal de uma rede de relações tem continuidade ao longo da vida, e as relações podem ser revistas. O importante, porém, é ter em mente que essa construção ativa a efetivação das relações sociais que têm início na infância, e que as crianças não somente aprendem e têm transmitidas relações com determinadas pessoas. Ou seja, mesmo no caso das interações regidas por parentesco, elas não apenas reproduzem o que recebem, mas, a partir desse quadro possível de relações, efetivam, recíproca e ativamente, algumas. Fazê-lo significa ter domínio sobre tratamentos apropriados para as diversas categorias de pessoas, porque só isso lhes permitirá ter a relação ativada de modo recíproco. Nessa atualização de relações potenciais, são estimuladas e mesmo auxiliadas pelos adultos, que as engendram em conversações que as posicionam ante um sem número de pessoas, e de modo contextualizado, mais ou menos jocoso ou respeitoso de acordo com os interlocutores. Se suas atividades não são divergentes das dos adultos, pelo simples motivo de que são informadas pelo mesmo aparato sociocultural, têm uma razão e um sentido construídos por elas próprias (COHN, 2000b, p. 212).

Ainda, segundo Cohn (2000a), um dos aspectos relacionados aos processos de aprendizagem vivenciados pela criança Xikrin está representado pelo termo mari, que na língua Kayapó, significa ouvir, fazer sentido, compreender, ensinar e aprender. Dessa forma, o processo de aprendizagem Kayapó envolve não só a transmissão de saberes, mas o fortalecimento dos órgãos sensoriais. Os Kayapó dizem que as crianças

[...] tudo sabem porque tudo vêm e ouvem, mas nada sabem porque são crianças. Olhos e ouvidos se desenvolverão, tornando-as capazes de efetivamente aprender, e de se engajar, por iniciativa própria, ou como membros de uma categoria de idade e, portanto, individual ou coletivamente, em relações de aprendizado (COHN, 2000a, p. 180).

Algo semelhante ocorre entre as crianças pequenas Maxakali que, segundo Alvares (2004, p. 54) circulam livremente entre as casas, ocupam o pátio central da aldeia com suas brincadeiras e são mensageiras entre os diversos grupos familiares, circulando pequenos objetos, notícias e acontecimentos. Possuem também a liberdade de participarem das refeições em outras casas, além das suas próprias. Mas, em contrapartida, devem dividir os alimentos que recebem com as outras crianças. Lição de sociabilidade que se aprende desde muito cedo - o consumo partilhado dos alimentos com seus iguais.

O tecido social se torna, desta forma, permeável à introdução da criança. É permitida a ela a circulação e a penetração em todas as suas dimensões. Desta forma, o aprendizado sobre a composição e os papeis sociais é vivenciado. Cumprindo um papel fundamental como construtoras ativas junto aos adultos, as crianças se apropriam do seu próprio universo social e das categorias de sentido que o compõe. Ao permitir o trânsito entre as diversas categorias sociais, as crianças, ao mesmo tempo em que aprendem, 
constroem, junto aos adultos, as relações sociais e a dinâmica da vida social e política do grupo. Este trânsito das crianças, claro, é orientado pelas relações dos mais velhos. Mas, mesmo quando as crianças são apenas o suporte das falas interpostas entre os adultos, elas são colocadas no foco de atenção da relação em causa. Forma sempre presentificada e experienciada do aprendizado social (ALVARES, 2004, p. 55).

Melissa Santana de Oliveira $(2004,2005)$ analisa a participação das crianças M’byiá Guarani, na casa de reza, no coral e na escola, da Aldeia Guarani M’Biguaçu em Santana Catarina, e do como elas se tornam centrais no processo de "valorização da tradição". As intenções da autora é mostrar como a construção da $O p \ddot{y}$ (casa de rezas Guarani), e mais especificamente, a formação do coral e a implantação da escola, revelam uma intenção pedagógica das lideranças na organização de espaços de ensinoaprendizagem da "tradição" voltados para a educação das crianças.

Na direção desta "valorização da tradição" é possível apontar três movimentos de suma importância: 1) A criação de uma escola na aldeia em 1996, no contexto mais amplo da conquista do direito à educação escolar diferenciada por parte dos povos indígenas no Brasil. Essa escola foi instituída a partir de uma decisão política das lideranças no intuito de propiciar aos alunos Guarani um estudo que permitisse o seu acesso aos conhecimentos não-índios mas, principalmente, o aprendizado da escrita e leitura da língua Guarani. 2) A formação do Coral Ÿrütchi Ovyj (Nuvens Azuis) em 1998. O coral performatiza músicas e danças Guarani, relacionadas a questões míticas e religiosas. 3) A construção, na mesma época, de uma Opÿ, feita de taquara, barro e coberta por palha, em frente à casa do Karaí. A existência de uma casa de rezas é considerado um fator fundamental na configuração da vida religiosa do grupo $(2005$, p. 76$)$.

O coral revela sobretudo um investimento consciente e sistemático no ensino-aprendizagem de cantos, danças e toques de instrumentos e de certas disposições, como a concentração (edjapitchaka). O aprendizado das crianças se dá ao mesmo tempo em que são imbuídas de desempenhar um papel de destaque na vida do grupo, tomando a posição de protetores, guardiões e guerreiros do grupo. O foco central da escola está voltado para o que os Guarani consideram ser o "conhecimento tradicional da sua cultura”. Esse conhecimento é tematizado por meio do desenvolvimento de projetos junto à liderança religiosa do grupo, o Karaí, tcheramõi (avô) de grande parte das crianças. Na casa de rezas, as crianças, desde cedo, participam das danças e no toque dos instrumentos (OLIVEIRA, 2005).

O "resgate e a valorização da tradição Guarani”" têm como elemento central a religiosidade, que tanto é acionada na criação de um ethos interno, como é eleita símbolo diacrítico na relação com os djuruá. A "valorização da tradição" significa fundamentalmente uma preocupação em "não esquecer-se de Nhanderu" e em manter uma comunicação intensa com este por meio das rezas. Centralizado que está nos saberes do Karaí, o "resgate da tradição" exige uma atitude pedagógica, de ensinoaprendizagem desses saberes. Essa pedagogia envolve a todos, e dá-se mediante um duplo movimento: uma "preocupação" em ensinar, por parte das gerações mais velhas, e um "interesse" em aprender, por parte das gerações mais jovens, entre estas as Kj̈ringu, de modo que tanto quem ensina como quem aprende são considerados sujeitos no processo de ensino-aprendizagem (OLIVEIRA, 2005, p. 87-88).

Analisando a participação das crianças neste processo, a autora atenta para a postura autônoma da atuação das crianças nas rezas justamente por ser uma escolha pessoal baseada no interesse em 
participar. Chama a atenção também que, tanto a participação no opji, quanto no coral e na escola, constituem o ensino-aprendizagem de determinadas posturas corporais e o desenvolvimento de certa resistência física e psicológica para se "aguentar".

Sarah Siqueira de Miranda (2009), em sua etnografia realizada junto aos Pataxó do Território Indígena de Coroa Vermelha, Santa Cruz Cabrália, no extremo sul da Bahia, apresenta o protagonismo das crianças Pataxó e sua importância nos processos de territorialização e no fortalecimento da identidade étnica e da cidadania deste povo, sobretudo, através da venda ambulante de artesanato. Como salienta a autora, ao percorrerem quilômetros de praias além dos limites que circunscrevem a Terra Indígena, elas reforçam e ampliam a apropriação simbólica do território. Ao se movimentarem pelo território, tornamse difusoras dos elementos diacríticos utilizados pela comunidade Pataxó no contínuo processo de legitimação da identidade étnica, dentre os quais a língua indígena, Patxohã, recriada no âmbito da Escola Indígena. A participação infantil em atividades produtivas representa, para essa comunidade, elemento essencial à formação de indivíduos plenamente aptos à vida social.

O trabalho, sobretudo, é por elas visto como algo comum e necessário a todos os índios de Coroa Vermelha, não constituindo as crianças exceção à regra. Há, portanto, uma ampla possibilidade de negociação entre as crianças e os pais: nos dias em que estão cansadas, ou mesmo sem disposição, quando algo mais interessante se lhes apresenta, é comum que consigam convencer os pais de que não precisam trabalhar naquele dia. Inúmeras vezes, inclusive, não trabalhar é decisão única e exclusiva das próprias crianças: "hoje vou empinar pipa", "vou participar do campeonato da escola". Em geral, não há recriminação por parte dos adultos. Não obstante constrangidas por uma série de restrições e obrigações específicas, nos domínios intra e extra-domésticos, impostas à sua incompleta maturidade biológica, se reconstroem continuamente como agentes (MIRANDA, 2009, p. 221).

Rogério Correia da Silva (2011) investigou as formas de sociabilidade, a transmissão do conhecimento e o aprendizado da criança na sociedade indígena Xakriabá, localizada na região norte do Estado de Minas Gerais, próximo à cidade de Januária, no Vale do São Francisco. Segundo o autor, as crianças participariam de "forma engajada" nas tarefas diárias a elas atribuídas de acordo com a idade e o gênero ${ }^{2}$. Nos diferentes aspectos da vida cotidiana, as crianças participam e aprendem o significado da vida entre parentes. "Em alguns momentos, ela é participante desta rede tendo papel de destaque na sua produção (elo entre diferentes grupos familiares, ao circular por entre as casas), em outros ela é produto desta rede (filho, neto, produto do casal) algo que se compartilha entre parentes” (SILVA, 2011, p. 35).

[...] nos chama a atenção a onipresença das crianças Xakriabá em todas as atividades da vida cotidiana da aldeia: das reuniões nas casas da comunidade às cerimônias religiosas, nos casamentos, nas atividades domésticas de seu grupo familiar voltadas para a manutenção da casa e para o cultivo de alimentos. Não há distinção entre espaços voltados exclusivamente para adultos e aqueles voltados para as crianças. De situações

\footnotetext{
${ }^{2}$ Existem muitos momentos coletivos em que participam juntos homens, mulheres e crianças. Todavia, chama-nos a atenção um uso segregado desses espaços segundo o gênero e idade. No espaço da casa temos, por exemplo, ocasiões em que somente as mulheres se reúnem como no preparo da comida. Dos homens, o espaço da sala e da varanda, as rodas de conversa, o jogo de futebol. As crianças participam de todos estes espaços destes e de outros momentos. As crianças à medida em que crescem vão participando dos espaços determinados pela orientação do grupo, mas também criando os seus próprios espaços organizando-se em grupos de pares (SILVA, 2011, p. 109).
} 
mais informais a momentos mais estruturados e formalizados de aprendizado, estes diversos momentos da vida social que propiciam o encontro entre adultos e crianças suscitam por sua vez uma diversidade de situações de comunicação e aprendizagem. Se a relação adulto-criança não é marcada pelo controle dos espaços por onde a criança circula, muito menos o é pelo controle do seu tempo, pela vigilância, pela imposição de regras. A criança participa das atividades do grupo, não existindo uma separação, por exemplo, entre o mundo produtivo e a infância. As crianças participam do universo feminino, das atividades produtivas, dos rituais (em alguns momentos como participantes, protagonistas, em outros, como observadoras). Há entre os adultos uma tolerância maior para com a ação infantil, respeitando seu tempo para realização das atividades e respeito também pela sua produção, valorizando suas possibilidades de realização (2011, p. 45).

A transmissão e aprendizagem horizontal de saberes entre as crianças encontra-se muito presente na ideia das crianças maiores se co-responsabilizarem pelos cuidados e educação das menores. Uma das cenas muito comuns nas Aldeias Xakriabá é, segundo Silva (2011), deparar-se com crianças maiores carregando as menores, alimentando-as, dando-lhes banho, ensinando-lhes tarefas simples da rotina da casa, como pegar lenha ou alimentar os cavalos.

Segundo Silva (2011), aos circularem pela aldeia, as crianças constroem noções de espaço e tempo, atreladas à participação em atividades do trabalho na roça, na tarefa de guiar o gado, durante as caçadas, nas brincadeiras e em tantas situações. Por outro lado, segundo a autor, a circulação das crianças pelo território está muito relacionada a sua participação em seu grupo familiar. Os meninos aprendem a gerir o tempo em que realizarão as atividades e autonomia para decidirem quando as farão. $\mathrm{O}$ tempo de execução da atividade torna-se assim um tempo distendido, sem pressa, podendo associar à tarefa principal as outras coisas do seu interesse como, por exemplo, as pilotagens, a coleta de frutos, as visitas rápidas à casa de parentes.

A pesquisa de Maria Geovanda Batista (2015) teve por objetivo identificar a agência das crianças Pataxó no processo de constituição de suas próprias culturas de infância nas aldeias Kaí, Pequi e Tibá em Cumuruxatiba, no município de Prado, no Extremo Sul da Bahia. Em sua análise, a autora incorpora algumas das formulações que os Pataxó elaboram sobre os processos de iniciação das crianças e das gerações mais jovens à rede de relações sociais de alteridade entre parentes e no contexto do cotidiano em suas aldeias e comunidades.

[...] distinguimos o brincar ou hãmiyá dos adultos e o hãmiyá dos kitok da seguinte forma. Partimos do pressuposto (inter e intra) geracional de que 'a condição comum aos seres humanos é a experiência da 'infância'. Não importa se, trata-se de um ser humano pequeno ou grande, se, uma criança, um jovem, velho ou adulto, é a infância e o devircriança, o signo dessa 'alteridade', o denominador comum entre os seres humanos e não numanos e, não, a adultez, tampouco a velhice'. São os adultos que já foram crianças um dia e não o contrário. Não são as crianças que devem ser compreendidas como futuros ex-adultos, mas, são os adultos que se transformaram em ex-crianças. E, porque, os jovens, adultos e anciãos já viveram seus tempos de criança, por isso, experimentaram e aplicaram sobre seus corpos, em si mesmos, o hãmiyá, teceram na sua respectiva geração as suas próprias culturas de infâncias e não poderão mais fazê-lo, a não ser, atualizar suas próprias narrativas de infâncias (já prontas e acabadas) que, diga-se de 
passagem, pouco ou nada mudarão, tendendo a continuar iguais a si mesmas (2015, p. 98, grifos da autora).

Segundo Batista (2015, p. 100), “[...] o kitoke e as outras crianças, do mesmo modo que os filhotes dos pássaros, bem-te-vis e dos outros animais da natureza, precisam ser cuidadas, alimentadas, encorajadas e seus corpos, produzidos socialmente, fabricados para que possam se defender e atender às exigências da vida". Batista concebe os kitok como agentes intertransculturais, (co) produtores, consumidores de culturas, de sua própria e de sua comunidade. Na terra indígena, ainda que provisória, à espera de demarcação, os kitoke as kitok lhe vão descobrindo, inventando, aprendendo, incorporando entre seus saberes práticos, ação e iniciativa e, portanto, atualizando o conhecimento e a cultura deste povo.

\section{Para concluir ou sobre os modos de produção de conhecimento entre os Kiriri}

Um dos estudos pioneiros sobre Kiriri, intitulado "Os Kariris de Mirandela: um grupo indígena integrado" de Maria de Lourdes Bandeira (1972), mesmo que enquadrado nos chamados "estudos de aculturação" (segundo a autora, o trabalho empírico permitiria um estudo sistemático do grupo e a documentação de seu estágio de aculturação), mostra-nos características da educação indígena Kiriri no que se refere aos aspectos como a responsabilidade dos pais e/ou mestres em relação ao ensino das artes às crianças, sendo que se os pais não soubessem os ofícios, seus filhos poderiam aprender com mestres e tias. No entanto, como salienta Bandeira (1972), o aprendizado da cerâmica ${ }^{3}$ (potes em diversos tamanhos, porrões, aribés, panelas, frigideiras, cuscuzeiros) é uma especialização feminina, que passa de mãe para filha. Quando as exceções ocorriam, constituía-se uma relação analógica à adoção. Outro elemento destacado por ela foi o não uso de castigos nos cuidados dos pais para com as crianças.

Dos seis anos em diante a menina aprende a fazer Imbé, louça, trançados e começa a ajudar a mãe. Entre oito e dez anos vai buscar água, ajuda na roça e ou freqüenta a escola (muito poucas). Os meninos começam mais tarde, aproximadamente entre oito e dez anos. Aprendem a fazer cêstos de cipós, caçuás, e se tiver pendor e interesse a tocar zabumba, caixa ou gaita. Depois de 10 anos seu trabalho na roça rende dinheiro. Tanto os meninos como as meninas cabe a responsabilidade dos irmãos menores durante a ausência dos pais. Geralmente cabe aos pais ensinar às crianças suas artes. Se porém o pai não sabe tocar qualquer instrumento, o filho pode aprender com um mestre mediante pagamento ou graciosamente. $\mathrm{O}$ mesmo se dá com as meninas no aprendizado de artes tais como costura, tecelagem (de rêde). Fazer louça é uma habilidade que passa de mãe para filha. Se a mãe não sabe, a filha não aprende. Só encontramos, na Cacimba Sêca, um único caso de louceira que aprendeu com a tia,

\footnotetext{
3“Quanto à forma, há potes arredondados e de forma esférica, porrões geralmente de forma ovóide (poucos em forma cônica), aribés em forma de meia calota. Potes, panelas e porrões são vasos de boca constrita. Os aribés, cuscuzeiros e frigideiras têm boca ampliada. As pinturas utilizam linhas e pontos. Motivos geométricos. A cerâmica depois de confeccionada deve secar ao sol por tempo mínimo de um dia. Em seguida é queimada em forno próprio. Para sustentar a vasilha no forno, preparam arcos de cipós cobertos com barro e de diâmetros variados. Os arcos são dispostos em ordem crescente de baixo para cima e a vasilha é encaixada na armação. O fogo é aceso embaixo da armação que fica suspensa à altura da boca do forno" (BANDEIRA, 1972, p. 60).
} 
assim mesmo porque morava com ela antes de casar, tornando-se sua filha adotiva (BANDEIRA, 1972, p. 71).

Macedo de Sá (2009), em sua pesquisa de mestrado realizada junto aos Kiriri, intitulada "Educação por outros olhares: aprendizagem e experiência cultural entre os índios Kiriri do sertão baiano", afirma que existem expressivas singularidades socioculturais reelaboradas e ressignificadas que formam a base do ethos grupal desse povo, onde se constrói e se realiza a experiência cultural da aprendizagem e os aprendizados que estruturam a sua cultura. Nesse sentido, conforme a autora, por meio da tradição Kiriri, disseminada pelas narrativas e demais experiências vivenciadas em grupo, são aprendidas, refletidas, reelaboradas e transmitidas normas sociais, valores e crenças pertinentes ao seu interativo e dinâmico contexto cultural. A experiência em si revela o próprio processo de aprendizagem se realizando. Aprender, para este povo, está longe de ser um abstracionismo em relação a sua configuração sociocultural, ou seja, aprender não significa ter que perder a referência. Para as crianças, os jovens e demais sujeitos Kiriri aprendentes, a linguagem oral, a narrativa é desveladora, reveladora e problematizadora do contexto cultural em que estão inseridas e, também, é o processo de formação e constituição desses mesmos sujeitos que narram, mestres e discípulos, indivíduos em trans-formação.

Macedo Sá (2009) mostrou a relação do uso de plantas no processo de aprendizado dos Kiriri, as experiências como constitutivas para memorização e aprendizagem das funções e identificações das plantas e dos universos cosmológicos indígenas. A autora ressalta que certas plantas são fundamentais para o campo religioso e para a construção da cultura Kiriri.

Dando continuidade às discussões produzidas a partir de sua pesquisa de mestrado, Macedo de Sá (2013), em sua tese de doutorado intitulada "A emergência da etnoaprendizagem no campo antropoeducacional: uma investigação etnológica sobre a aprendizagem como uma experiência sociocultural", a autora pretendeu dar maior fundamentação e desenvolvimento ao conceito de etnoaprendizagem, cujos aportes teóricos se inspiram nas contribuições da antropologia da educação, da etnometodologia e na teoria da complexidade.

No capítulo quarto da tese, Macedo de Sá (2013) recupera a discussão, já desenvolvida em seu mestrado, sobre aprendizagem e experiência cultural entre os índios Kiriri do sertão baiano. Conforme a autora, a aprendizagem com a terra e com o "mato" entre os Kiriri é uma relação umbilical por eles se considerarem filhos da terra.

$\mathrm{Na}$ terra, no mato, na natureza, na aldeia, os meninos e as meninas Kiriri, observando, escutando, imitando, reelaborando, reconstruindo, desconstruindo os ensinamentos. Acompanhando seus pais, avós, tios, irmãos e amigos mais velhos, as crianças vão desvendando os segredos da vida, da natureza, e compreendendo seu lugar, seu papel social dentro da sociedade Kiriri. Assim, aprender a ser Kiriri é um exercício diário! A identidade indígena Kiriri é ensinada no cotidiano (MACEDO DE SÁ, 2013, p. 91).

Pela manhã, logo cedo, os chefes de família, os jovens e as crianças, que não estudam neste turno, vão para roça ainda com o sol fraquinho do amanhecer sertanejo. Já as mulheres se dirigem, também, para a roça com seus companheiros e filhos ou acordam 
um pouco mais tarde e preparam o café, botam o feijão no fogo, arrumam a casa, confeccionam alguns artesanatos ou vão colher as sementes necessárias para tal, ou, ainda, podem ir pegar barro para as louças com quem estiver em casa (MACEDO DE SÁ, 2013, p. 92).

Não existem muitas distinções entre o que é ensinado e o que é aprendido por meninos ou meninas. Até mesmo a questão da sexualidade é tratada praticamente da mesma forma para ambos os sexos. O que é aprendido por um, também, pode ser aprendido pelo outro. Meninos e meninas cozinham, cuidam dos artesanatos, vão para a roça, para a escola e praticam os rituais. Só em algumas atividades existe uma maior incidência de um determinado sexo, mas não chega a ser uma proibição. Mesmo com relação aos rituais, há um equilíbrio entre os sexos: as mulheres, geralmente, são as responsáveis pela comunicação com os encantos, já os homens assumem os postos de caciques ou pajés, mas nenhuma dessas funções rituais é marcada totalmente ou restrita para alguém. Esta é uma questão de dom, ou seja, de nascer com "o significado", de aprender com os encantos, através dos sonhos, do sofrimento causado pelas doenças de iniciação, dos diálogos privados com as entidades, que podem levar à loucura, pois estes ritos de passagem são momentos característicos da aprendizagem daqueles privilegiados pelo poder de comunicação com o mundo paralelo (MACEDO DE SÁ, 2013, p. 93).

Ademais, conforme Macedo de Sá (2013), ouvindo e aprendendo sobre os encantos, as qualidades dos animais, as hierarquias xamanísticas, os Kiriri fazem a manutenção dos seus símbolos culturais, reforçam seu lugar no mundo ocidental, valorizam suas crenças e identidades grupais, se afirmam e se reconhecem enquanto índios na sua especificidade cultural, étnica. "A aprendizagem, enquanto experiência seria, então, processo de mediação entre o sujeito e a sociedade e vice-versa, ou seja, a experiência em si é o próprio processo de aprendizagem inserido no contexto de diversos símbolos compartilhados que constituem a cultura" (MACEDO, 2013, p. 98).

$\mathrm{Na}$ comunidade Kiriri, o trabalho executado pelas crianças tem um sentido ético/moral e, portanto, está implicado na formação da pessoa Kiriri. Nesse sentido, como sugere Macedo de Sá (2013, p. 101), “[...] os processos de etnoaprendizagens da prática agrícola são formas simbólicas importantes de lidar com a terra", pois, conforme este povo, o trabalho, além de ser economicamente importante, é também uma prática cosmologicamente essencial para o equilíbrio e para a formação da pessoa. “[...] ensinar aos pequenos como trabalhar com a terra, através dos instrumentos em miniatura que os pais fabricam e da observação exemplar, é um procedimento etnoaprendente de sobrevivência e também de reverência à entidade que é uma fonte de vida, uma 'mãe boa', a terra' (2013, p. 101).

[...] nas suas diversas práticas cotidianas, ou seja, narrando, olhando, escutando, plantando, caçando, dançando, nadando, imitando, ou silenciando, o processo educacional se dá em toda sua complexidade e plenitude e cada indivíduo se compreende no seu papel social no grupo, no seu loci cultural. Se há a possibilidade de sintetizar numa palavra, a partir do nosso processo de compreensão, essa experiência, poderíamos dizer que a exemplaridade mutualista é o que caracteriza a experiência aprendente entre os Kiriri. Mesmo com todos os problemas sociais e conflitos internos, como é o caso do faccionalismo no grupo, a aprendizagem se revela não fragmentada, pois os referenciais histórico-culturais aparecem de forma conjugada em toda experiência aprendente, ou seja, as experiências vividas estão profundamente 
relacionadas aos processos e conteúdos a serem aprendidos, aos diversos tipos de saberes que se complementam em prol da aprendizagem (2013, p. 102).

Em defesa das características socioantropológicas das etnoaprendizagens, a autora conclui que fenômenos educacionais, por sua emergência complexa, não podem ser reduzidos a perspectivas homogeneizadoras, fragmentadas, apartados de seus referenciais histórico-culturais, posto que "[...] as experiências vividas estão profundamente relacionadas aos processos e conteúdos a serem aprendidos, aos diversos tipos de saberes que se dinamizam e complementam em prol da aprendizagem" (MACEDO DE SÁ, 2013, p. 158).

Chates (2011), em sua dissertação de mestrado intitulada “A domesticação da escola realizada por indígenas: uma etnografia histórica sobre a educação e a escola Kiriri”, afirma que a educação Kiriri diz respeito aos processos próprios de produção e transmissão dos conhecimentos, relacionando-se com a educação na roça, à educação na família e ao campo da ciência espiritual. Os principais saberes indígenas Kiriri se manifestam nas práticas de produção de subsistência, a exemplo do artesanato, a agricultura, os ritos, os mitos ancestrais, como também as festas e práticas culturais. Ademais, segundo a autora, “o uso medicinal e ritual das plantas é um ponto que considero extremamente importante para a compreensão das práticas Kiriri e, consequentemente, do seu processo educativo” (CHATES, 2011, p. 137).

Podemos apontar algumas questões relacionadas às duas categorias nativas centrais encontradas sobre educação indígena: a educação na roça, que está diretamente ligada a um dos elementos centrais evocados pelos Kiriri como mais importante para eles: a Terra; já a educação na familia, se liga diretamente a algumas categorias nativas constantemente evocadas: histórias de tradição, que são passadas de pai para filho e se referem não somente a narrativas, mas também a outros conhecimentos, inclusive sobre o plantio, como indicou um informante: "Olhe, meu filho, a mandioca, você planta ela agora...", pois "Vamos supor, que você planta ela agora, porque a mandioca, ela é mais de um ano, né? Se você passar de um ano pra dois, aí, ela afofa, né? Já não presta mais pra fazer, não sai mais aquela farinha de boa qualidade". Além disso, pude observar em visita a Dona Amélia, mãe de Dona Odisse e Seu Dionísio, que a maioria das histórias que ela me contou é conhecida por filhos/as e netos/as, que me contaram antes ou depois da agradável visita (2011, p. 138).

Santana (2007), em sua pesquisa intitulada "A produção dos discursos sobre cultura e religião no contexto da educação formal: o que pensam/querem os Kiriri de sua escola?", ao refletir sobre a relação dos saberes tradicionais com a escola, aponta para uma compreensão nativa de "índio espiritual", a partir da fala do cacique Lázaro, que diz respeito ao modo de conceber o processo de aprendizagem entre esse povo. Segundo Lázaro, “[...] o índio é espiritual. O que falo, poucos professores que vêem aqui entendem. Os índios mais novos também não entendem. Aprendi porque nasci espiritual” (SANTANA, 2007, p. 84).

Os Kiriri afirmam-se, transformam-se e inventam-se a partir de concepções de mundo de seu universo cultural, simbolizadas no que eles definem como os saberes da tradição. Se na fala de muitos Kiriri o sentido da tradição pode parecer preso ao tempo, voltando-se a um passado imemorial, na prática, nas ações cotidianas, no modo de ser Kiriri, tradições vão sendo “inventadas", no sentido dado por Roy Wagner (2010), a partir das necessidades concretas, das relações de poder travadas internamente e 
externamente (com os regionais) e dos novos sentidos que este povo vai atribuindo às novas experiências.

No caso Kiriri, a memória coletiva vai se constituindo numa espécie de caleidoscópio composto por vivências, ancestralidades, princípios de Arcké, espaços e lugares, tempos, sentimentos, percepções/sensações, objetos, sons e silêncios que reconstroem e rememoram os modos de ser, hoje, Kiriri. Nesse sentido, é preciso concordar com Maria Kiriri, quando afirma: "Não vivemos sem nossas tradições" (SANTANA, 2007, p.?).

Hildonice Batista (2008), em sua pesquisa de mestrado, intitulada "Bedzé Wò Hibatèdè conhecimentos ressonantes: diálogos entre a educação transdisciplinar e a práxis indígena Kiriri”, apresenta a existência de noções diferenciadas de educação e de produção de conhecimento, indicando que a noção diferenciada do que venha a ser o aprendizado e a produção de conhecimento para os Kiriri está interligada àasua historicidade e seus valores. Por meio de uma aprendizagem livre, as crianças Kiriri desenvolvem as várias habilidades do ser humano a partir de diferentes contextos. Através de uma pedagogia do exercício da observação silenciosa e constante, e o ouvir para refletir e prestar atenção. Os variados eventos como: pesca, dança, grafismo no corpo e no artesanato, caminhada na mata, trabalho com a terra e barro constituem espaços de aprendizagem cujos conhecimentos são produzidos de acordo com as necessidades cotidianas, pela disposição dos aprendizes e pela tradição oral. De modo que as práticas próprias de transmissão de conhecimentos dos Kiriri se apresentam no sentido de reconhecimento de um saber oriundo da experiência vivenciada, representando um constante (re) fazer a cada novo aprendiz e a cada nova realidade, e não uma representação da totalidade cultural.

\section{Referências}

ALVARES, Myriam Martins. Kitoko Maxakali: a criança indígena e os processos de formação, aprendizagem e escolarização. Anthropológicas, ano 8, v, 15, n.1, p. 49-78, 2004. Disponível em:

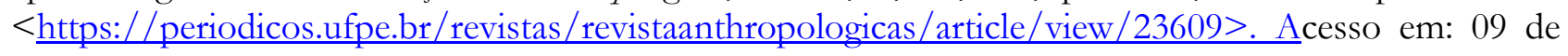
maio de 2017.

Criança e transformação: os processos de construção de conhecimento. In: TASSINARI, Antonella Maria Imperatriz; GRADO, Beleni Saléte; ALBUQUERQUE, Marcos Alexandre dos Santos (Orgs). Educação indígena: reflexões sobre noções nativas de infância, aprendizagem e escolarização. Florianópolis: Ed. da UFSC, 2012.

ARAÚJO, Sheila Alves de. A criança indígena nos estudos acadêmicos no Brasil: uma análise das produções científicas (2001 - 2012). 158 p. 2014. Dissertação (Mestrado em Educação) - Universidade Federal de Pará, Belém, 2014.

BANDEIRA, Maria de Lourdes. Os Kariris de Mirandela: um grupo indígena integrado. Salvador: UFBA, 1972. (Estudos Baianos, 6).

$4 \quad$ Por aproximação, esse título pode ser traduzido como instrumento para caminhar até nossa morada, pois na língua Kiriri Bedzé significa cabo de instrumento, Wó significa caminhar e Hibatèdè significa nossa morada (BATISTA, 2008, p. 19). 
BATISTA, Hildonice. Bedzé Wò Hibatèdè - conbecimentos ressonantes: diálogos entre a educação transdisciplinar e a práxis indígena Kiriri. 219 p. 2008. Dissertação (Mestrado em Educação) Universidade Federal da Bahia, Salvador, 2008.

BATISTA, Maria Geovanda. Culturas de infâncias indígenas: processos de subjetivação e protagonismo dos kitok entre os Pataxó na Costa do Descobrimento. 201 p. 2015. Tese (Doutorado em Educação) Universidade do Estado da Bahia, Salvador, 2015.

BERGAMASCHI, Maria Aparecida. Enquanto o encanto permanece: processos e práticas de escolarização nas aldeias Guarani. 273 p., 2005. Tese (Doutorado em Educação) - Programa de Pós Graduação em Educação, Universidade Federal do Rio Grande do Sul. Porto Alegre, 2005.

BORGES, Júlio César; NIEMEYER, Fernando. Cantos, curas e alimentos: reflexões sobre regimes de conhecimento Krahô. Revista de Antropologia, v. 55, n. 1, p. 255-290, 2012. Disponível em:

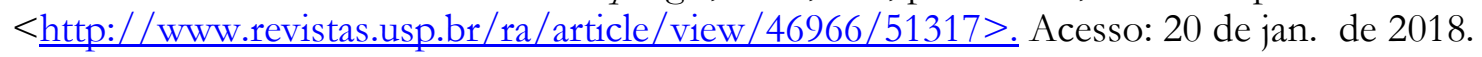

CARNEIRO DA CUNHA, Manuela. Políticas culturais e povos indígenas. In: CARNEIRO DA CUNHA, Manuela; CESARINO, Pedro (Orgs.). Políticas culturais e povos indígenas. São Paulo: Cultura Acadêmica, 2014, p. 9-24.

. Questões suscitadas pelo conhecimento tradicional. Revista de Antropologia. v, 55, n. 1, p. 171206, 2012. Disponível em: < http://www.revistas.usp.br/ra/article/view/46971>. Acesso em: jul. 2017.

Cultura com aspas e outros ensaios. São Paulo: Cosac Naify, 2009.

CHATES, Taíse de Jesus. A domesticação da escola realizada por indígenas. uma etnografia histórica sobre a educação e a escola Kiriri. 2011, 181 p.. Dissertação (Mestrado em Antropologia) - Programa de PósGraduação em Antropologia, Universidade Federal da Bahia, Salvador, 2011.

CODONHO, Camila. Aprendendo entre pares: a transmissão horizontal de saberes entre as crianças indígenas Galibi-Marworno. 134 p.. Dissertação (Mestrado em Antropologia Social) - Universidade Federal de Santa Catarina, Florianópolis, 2007.

Cosmologia e infância Galibi-Marworno: aprendendo, ensinando, protagonizando. In: TASSINARI, Antonella Maria Imperatriz; GRADO, Beleni Saléte; ALBUQUERQUE, Marcos Alexandre dos Santos (Orgs). Educaşão indigena: reflexões sobre noções nativas de infância, aprendizagem e escolarização. Florianópolis: Ed. da UFSC, 2012, p. 53-75.

COELHO, Luciano Silveira; DEBORTOLI, José Alfredo Oliveira. Corporalidade e engajamento: participação e aprendizado de crianças e adultos em contextos indígenas. In: ARROYO, Miguel G.; SILVA, Maurício Roberto (Orgs.). Corpo infancia: exercícios tensos de ser criança - por outras pedagogias dos corpos. Petrópolis, RJ: Vozes, 2012, p. 131-152.

COHN, Clarice. A criança indígena: a concepção Xikrin de infância e aprendizado. 185 p. Dissertação (Mestrado em Antropologia) - Programa de Pós-Graduação em Antropologia, Universidade de São Paulo, São Paulo, 2000a.

- Crescendo como um Xikrin: uma análise da infância e do desenvolvimento infantil entre os Kayapó-Xikrin do Bacajá. Revista de Antropologia, São Paulo, USP, v. 43, n.2. 2000b. Disponível em:

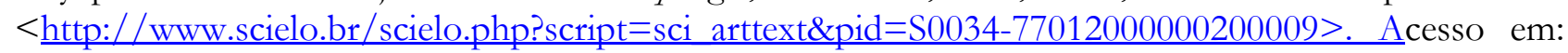
15 de ago. de 2017. 
Noções sociais de infância e desenvolvimento infantil. Cadernos de Campo, Ano 10, v. 9, p. 13-

26, 2000c. Disponível em: <http://www.revistas.usp.br/cadernosdecampo/article/view/53068>. Acesso em: ago. 2017.

. A experiência da infância e o aprendizado entre os Xikrin. In: SILVA, Aracy; MACEDO, Ana Vera Lopes da Silva \& NUNES, Ângela (Orgs.). In: Crianças indígenas: ensaios antropológicos. São Paulo: Global, 2002, p. 117-149.

Educação escolar indígena: para uma discussão de cultura, criança e cidadania ativa. Revista Perspectiva, Florianópolis, v. 23, n.02, p. 485-515.

2005a. Disponível em: < https://periodicos.ufsc.br/index.php/perspectiva/article/view/9804>. Acesso em: 08 de mai. 2017.

. Antropologia da criança. Rio de Janeiro: Jorge Zahar, 2005.

- Concepções de infância e infâncias: um estado da arte da antropologia da criança no Brasil.

Civitas, Porto Alegre, v. 13, n. 2, p. 221-244, maio-ago. 2013. Disponível em: $<$ http://revistaseletronicas.pucrs.br/ojs/index.php/civitas/article/view/15478>Acesso em: 05 de jul. 2017.

GÓES, Paulo Roberto Homem de. Ciência boa: modos de aprendizado, percepção e conhecimento entre os Katukina/Pano. Revista de Antropologia, v, 55, n. 1, p. 171-206, 2012. Disponível em: < http://www.revistas.usp.br/ra/article/view/46964>. Acesso em: 08 de julho de 2017.

GOMES, Ana Maria. Um (possível) campo de pesquisa: aprender a cultura. In: TOSTA, Sandra Pereira; ROCHA, Gilmar (Orgs.). Diálogos sem fronteira: história, etnografia e educação em culturas iberoamericanas. Belo Horizonte: Autêntica, 2014, p. 205-220.

INGOLD, Timothy. Da transmissão de representações à educação da atenção. Educação. Porto Alegre, v. 33, $\quad$ n. 1 , p. 6-25, 2010. Disponível em: $<$ http://revistaseletronicas.pucrs.br/ojs/index.php/faced/article/view/6777>. Acesso em: $08 \mathrm{de}$ mar. 2018.

LIMA, Edilene Coffaci. A internacionalização do kampô (via ayahuasca): difusão global e efeitos locais. In: CARNEIRO DA CUNHA, Manuela; CESARINO, Pedro (Orgs.). Politicas culturais e povos indigenas. São Paulo: Cultura Acadêmica, 2014, p. 91-112.

LOPES DA SILVA, Aracy. Pequenos "xamãs": crianças indígenas, corporalidade e escolarização. In: LOPES DA SILVA, Aracy; NUNES, Ângela; MACEDO, Ana Vera Lopes da Silva (Orgs.). Crianças indígenas: ensaios antropológicos. São Paulo: Global, 2002, p. 37-63.

LUCIANO, Gersem dos Santos. O indio brasileiro: o que você precisa saber sobre os povos indígenas no Brasil de hoje. Brasília: MEC/SECAD; LACED/Museu Nacional, 2006. (Coleção Educação Para Todos. Série Vias dos Saberes n. 1).

MACEDO DE SÁ, Silvia Michele Lopes. Emergência da etnoaprendizagem no campo antropoeducacional: uma investigação etnológica sobre a aprendizagem como experiência sociocultural. 2013. 175 p. Tese (Doutorado em Educação) - Universidade Federal da Bahia, Salvador, 2013.

. Educação por outros olhares: aprendizagem e experiência cultural entre os índios Kiriri do Sertão Baiano. Dissertação (Mestrado em Educação) - Programa de Pós-Graduação em Educação, Universidade Federal da Bahia, Salvador, 2009. 
MCCALLUM, Cecilia Anne. Alteridade e sociabilidade Kaxinauá: perspectivas de uma antropologia da vida diária. Revista Brasileira de Ciências Sociais. vol. 13 n. 38, São Paulo, Ou.1998. Disponível em: <http://www.scielo.br/scielo.php?pid=S010269091998000300008\&script=sci abstract\&tlng=pt $>$. Acesso em: 09 de ago. 2017.

. Anatomia funcional na perspectiva indígena: Adaptação ontológica ou mudança de paradigma? ENCONTRO ANUAL DA ANPOCS - Associação Nacional de Pós-Graduação e Pesquisa em Ciências Sociais, 35, 24 a 28 de outubro, Caxambu, Minas Gerais, 2011.

MELO, Clarissa Rocha de. Aprendizado, percepção e conhecimento Guarani: possibilidades de diálogo entre saberes distintos. In: TASSINARI, Antonella Maria Imperatriz; ALMEIDA, José Nilton de; RESENDÍZ, Nicanor Rebolledo (Orgs.). Diversidade, educação e infância: reflexões antropológicas. Florianópolis, SC: Ed. Da UFSC, 2014, p. 295-319.

. Uma escuta do mundo: processos de ensinar e aprender entre os Guarani. In: TASSINARI, Antonella Maria Imperatriz; GRADO, Beleni Saléte; ALBUQUERQUE, Marcos Alexandre dos Santos (Orgs). Educação indigena: reflexões sobre noções nativas de infância, aprendizagem e escolarização. Florianópolis: Ed. da UFSC, 2012, p. 117-137.

MELO, Valéria M. C. de; GIRALDIN, Odair. Os Akwe-Xerente e a busca pela domesticação da escola. Revista Tellus, ano 12, n. 22, jan./jun, 2012. Disponível em: < http://www.tellus.ucdb.br/index.php/tellus/article/view/279>. Acesso em: 15 de mai. 2017.

MIRANDA, Sarah Siqueira de. Aprendendo a ser Pataxó: um olhar etnográfico sobre as habilidades produtivas das crianças de Coroa Vermelha, Bahia. 244 p. 2009. Dissertação (Mestrado em Ciências Sociais)- Universidade Federal da Bahia, Salvador, 2009.

NUNES, Angela. No tempo e no espaço: brincadeiras das crianças A'uwê-Xavante. In: LOPES DA SILVA, Aracy; NUNES, Ângela; MACEDO, Ana Vera Lopes da Silva (Orgs.). Crianças indígenas: ensaios antropológicos. São Paulo: Global, 2002, p. 64-99.

OLIVEIRA, Joana Cabral de. "Vocês sabem porque vocês viram"! reflexão sobre modos de autoridade do conhecimento. Revista de Antropologia, v. 55, n.1, p. 51-74, 2012. Disponível em: <http://www.revistas.usp.br/ra/article/view/46959/66694>. Acesso em: 06 de jan. 2018.

OLIVEIRA, Melissa Santana de. Nhanhembo'é: infância, educação e religião entre os Guarani de M'Biguaçu, SC. Cadernos de Campo, n. 13, p. 75-89, 2005. Disponível em: $<$ http://www.revistas.usp.br/cadernosdecampo/article/view/50238/54352>. Acesso em: 09 de mai. 2017.

. Kyringuè i Guarani: infância, educação e religião entre os Guarani de M’Biguaçu. 112 p. Dissertação (Mestrado em Antropologia Social)- Programa de Pós-Graduação em Antropologia Social, Universidade Federal de Santa Catarina, Florianópolis, 2004.

SAÉZ, Oscar Calávia; NAVEIRA, Miguel Carid; GIL, Laura Pérez. O saber é estranho e amargo: sociologia e mitologia do conhecimento entre os Yaminawa. Campos, v. 9, p. 9- 28, 2003. Disponível em: < https://revistas.ufpr.br/campos/article/view/1596/1344>. Acesso em: 20 de dez. 2017.

SANTANA, José Valdir Jesus de. A produção dos discursos sobre cultura e religião no contexto da educação formal: o que pensar/querem os kiriri de sua escola? 111 p. Dissertação (Mestrado em Educação) - Universidade Estadual da Bahia, Salvador, 2007. 
SILVA, Rogério Correia da. Circulando com os meninos: infância, participação e aprendizagens de meninos indígenas Xakriabá. 228 p. Tese (Doutorado em Educação) - Universidade Federal de Minas Gerais, Belo Horizonte, 2011

TASSINARI, Antonella Maria Imperatriz; GRADO, Beleni Saléte; ALBUQUERQUE, Marcos Alexandre dos Santos (Orgs). Educação indígena: reflexões sobre noções nativas de infância, aprendizagem e escolarização. Florianópolis: Ed. da UFSC, 2012.

Concepções indígenas de infância no Brasil. Revista Tellus, ano, 7, n. 123, p. 11-25, 2007. Disponível em: <http://www.tellus.ucdb.br/index.php/tellus/article/view/138>. Acesso em: 17 de mai. 2017.

. O que as crianças têm a ensinar a seus professores? Antropologia em Primeira Mão, v. 129, Universidade Federal de Santa Catarina, Florianópolis, 2011, p. 1-16.

Introdução: Sobre noções nativas e antropológicas em educação indígena. In: TASSINARI, Antonella Maria Imperatriz; GRADO, Beleni Saléte; ALBUQUERQUE, Marcos Alexandre dos Santos (orgs). Educação indígena: reflexões sobre noções nativas de infância, aprendizagem e escolarização. Florianópolis: Ed. da UFSC, 2012, p. 15-22.

. COHN, Clarice. Escolarização indígena entre os Karipuna e Mebengokré Xikrin: uma abertura para o outro. In: TASSINARI, Antonella Maria Imperatriz; GRADO, Beleni Saléte; ALBUQUERQUE, Marcos Alexandre dos Santos (Orgs). Educação indígena: reflexões sobre noções nativas de infância, aprendizagem e escolarização. Florianópolis: Ed. da UFSC, 2012, p. 247-274.

Ajudando e aprendendo: a participação de crianças em atividades produtivas da agricultura familiar. In: TASSINARI, Antonella Maria Imperatriz; ALMEIDA, José Nilton de; RESENDÍZ, Nicanor Rebolledo (Orgs.). Diversidade, educação e infância: reflexões antropológicas. Florianópolis, SC: Ed. da UFSC, 2014a, p. 97-131.

. Práticas corporais indígenas em espaços interculturais: entre o ritual, o trabalho e o esporte. In: TASSINARI, Antonella Maria Imperatriz; ALMEIDA, José Nilton de; RESENDÍZ, Nicanor Rebolledo (Orgs.). Diversidade, educação e infância: reflexões antropológicas. Florianópolis, SC: Ed. da UFSC, 2014b, p. 163-196.

et. al. Educação, infância e diversidade: desafios à Antropologia e às políticas públicas. In: MONTARDO, Deise Lucy O.; RUFINO, Márcia Regina C. F. (Orgs.). Saberes e ciência plural: diálogos e interculturalidade em Antropologia. Florianópolis, SC: Editora da UFSC, 2017, p. 99-121.

WAGNER, Roy. A invenção da cultura. São Paulo: Cosac Naify, 2010. 